This is a pre-print that is currently undergoing peer-review (8-30-2021)

Adolescents Provide more Complex Reasons for Lowering the Voting Age than Adults Benjamin Oosterhoff ${ }^{1}$, Laura Wray-Lake ${ }^{2}$, \& K. Paige Harden ${ }^{3}$

${ }^{1}$ Department of Psychology, Montana State University, 305 Traphagen Hall, Bozeman, MT 59717

${ }^{2}$ Department of Social Welfare, University of California, 337 Charles E. Young Dr. East Los Angeles, CA 90095

${ }^{3}$ Department of Psychology, University of Texas Austin, 108 E. Dean Keeton Stop \#A8000, Austin, TX 78712

Address correspondence to:

Benjamin Oosterhoff

Department of Psychology

Montana State University

428C Traphagen Hall

Bozeman, MT 59717

USA

E-mail: Benjamin.oosterhoff@montana.edu

Phone: 517-897-4160

ACKNOWLEDGEMENT: We would like to thank Daniel Hart for his helpful feedback on previous drafts of this manuscript. 


\begin{abstract}
Debates about lowering the voting age often center on whether 16 and 17-year-olds possess sufficient cognitive capacity and political knowledge to participate in politics. Little empirical research has examined age differences in adolescents' and adults' complexity of reasoning about political issues. We surveyed $N=778$ adults $($ Mage $=38.5, S D=12.5)$ and $N=$ 39716 and 17-year-olds concerning judgements and justifications about whether the US should change the minimum voting age. Justifications for changing the voting age were coded for integrative (i.e., integrating multiple perspectives to form a judgment about changing the voting age), elaborative (i.e., providing multiple reasons to support the same judgement about changing the voting age), and dialectic (i.e., recognizing multiple differing perspectives on changing the voting age) complexity of reasoning. Bayesian regressions indicated that adolescents provided greater integrative and elaborative complexity in their reasoning to change the voting age than adults. Adolescents and adults did not meaningfully differ in their dialectic complexity. Findings are consistent with past research indicating that adolescents possess the cognitive capacity and political knowledge to vote in US elections.
\end{abstract}

Keywords: voting; adolescence; rights and responsibility; politics 


\section{Adolescents Provide More Complex Reasons for Lowering the Voting Age than Adults}

In recent years, scholars and policymakers have considered whether the US minimum voting age should be changed to 16 years of age (e.g., Oosterhoff et al., 2021; Wray-Lake et al., 2020). The minimum voting age for national elections is currently 16 years in 10 countries including Argentina, Austria, Brazil, Cuba, Ecuador, Malta, Nicaragua, the Isle of Man, Jersey, and Guernsey. Additionally, a few small US municipalities have expanded the voting age for local elections to include 16 and 17-year-olds, including Tacoma Park and Greenbelt, Maryland. Proponents of expanding the voting age highlight the social benefits of increasing political representation and encouraging civic engagement (Hart \& Atkins, 2011). Despite these advantages, only about $40 \%$ of US adults support changing the voting age, with those opposed primarily concerned that adolescents possess insufficient knowledge and cognitive ability to make an informed political decision (Wray-Lake et al., 2020).

Past research evaluating age differences in political knowledge has been mixed. Some evidence suggests that 16 and 17-year-olds have similar levels of political knowledge as adults (Hart \& Atkins, 2011; Hart \& Youniss, 2017; Wagner et al., 2012), while one study found that adolescents have lower political knowledge compared to adults (Chan \& Clayton, 2006). This research has generally examined 'propositional' political knowledge, which pertains to factual aspects of the political system such as the number of senators representing a state. But, political engagement involves much more than procedural knowledge about government and history. Although people who have more propositional political knowledge do tend to engage in more political participation (Campbell \& Niemi, 2016), propositional knowledge does not predict other indicators of political reasoning, such as making accurate judgments about the credibility of news information (Kahne \& Bowyer, 2017). Making decisions about complex political and 
social issues requires sophisticated reasoning about political viewpoints and not just factual knowledge about the political system.

Accurately measuring political reasoning ability poses a methodological challenge because few social issues have clear, consistent, and objectively correct responses. Rather than focusing on the content of political arguments, one strategy would be to analyze the structure of the argument. Research in cognitive science has a long history of examining the integrative complexity of political arguments by quantifying participants' reasoning about social issues regardless of their position on the issues (e.g., Conway et al., 2012). Integrative complexity is the extent to which people integrate multiple perspectives to form a judgment about an issue and can be separated into two components: dialectical and elaborative complexity. Whereas dialectical complexity entails the recognition of multiple differing perspectives on an issue (e.g., reasons to support lowering the voting and reasons to oppose lowering the voting age), elaborative complexity entails providing multiple reasons to support the same judgment (e.g., multiple reasons to oppose lowering the voting age). Examining the integrative, dialectical, and elaborative complexity of reasoning in justifications concerning political issues-including whether the US should change the voting age-may therefore represent one way to measure adolescents' and adults' ability to reason about political issues. If 16 and 17-year-olds lack the capacity to participate in politics, their justifications for changing the voting age should have lower integrative, dialectical, and elaborative complexity relative to adults.

Past research, theory, and public opinion data produce three plausible hypotheses regarding age differences in the complexity of reasoning regarding lower the voting age. First, the domain-specificity theory of integrative complexity proposes that people provide more complex reasoning for issues that are more personally relevant compared to those that are less 
relevant (Conway et al., 2001). From this perspective, both adolescents and adults would be expected to have more complex reasoning for some issues and less for others; yet, multiple political issues disproportionately affect adolescents, such as education, environmentalism, and gun control. Expanding the voting age to include 16 and 17-year-olds would reasonably have a larger impact on youth relative to adults and thus may be more relevant for teens. Consistent with domain-specificity theory, adolescents may have higher integrative, elaborative, and dialectic complexity in their reasoning about changing the voting age relative to adults.

Second, empirical studies of cognitive development and cognitive aging have found that late adolescents (ages 16-17 years) perform as well as adults-or better-on many different tests of cognitive ability (Lee et al., 2008; Steinberg et al., 2009). In fact, across nearly all tests of cognitive ability, the average performance of 16- to 17-year-olds is higher than the average performance of people over the age of 65 , who currently make up more than a quarter of US voters (Fabina, 2021). Consistent with this past research, adolescents may have similar or higher levels of integrative, elaborative, and dialectic complexity in their reasoning about changing the voting age relative to adults.

Third, the theory of crystallized intelligence argues that cultural and factual information increases linearly across adulthood, until very old age (Baltes, 1987), suggesting that political knowledge may grow across the lifespan with adolescents starting lower than adults. Adults' lay theories conform to this idea, as public opinion data indicate that adults believe youth have insufficient cognitive ability and knowledge to participate in politics (Wray-Lake et al., 2020). Consistent with this research, adolescents may have lower levels of integrative, elaborative, and dialectic complexity in their reasoning about changing the voting age relative to adults. 
The current study has two aims. The first aim is to replicate past public opinion research indicating that the majority of adults do not support lowering the voting age because they think adolescents' lack sufficient political knowledge and cognitive ability to vote (Wray-Lake et al., 2020). The second aim is to test competing hypotheses regarding adolescents' political reasoning by examining age differences between 16 and 17-year-olds and adults in their integrative, elaborative, and dialectic complexity for their reasons about whether the US should change the minimum voting age to 16 years. In conducting this analysis, it was important to examine alternative explanations for any age-group differences and test the generalizability of the proposed effect. We thus controlled for response word count and judgements about changing the voting age, as longer responses are likely to be more complex and those who are unsure about changing the voting age likely provide greater dialectic complexity (i.e., recognizing multiple perspectives) in their reasoning. Expanding voting rights — including lowering the voting age—is also a highly partisan issue (Hannity, 2019). Thus, to test the generalizability of the proposed findings, analyses explored whether age differences in complexity differed across political ideology.

\section{Methods}

\section{Participants and Procedures}

Data were collected in the Spring of 2019. A total of 1,175 adolescents and adults participated in this study. Of these participants, 39716 and 17-year-olds (65\% female) were recruited from across the US using targeted advertising on social media. The sample consisted of a relatively equal number of $16(n=201)$ and $17(n=196)$ year-olds. Youth identified as nonHispanic White (69.0\%), Hispanic or Latinx (11.1\%), Black or African American (6.5\%), Asian (8.8\%), American Indian or Alaska Native (4.2\%), 1.0\% identified as a different race or 
ethnicity, and $14.11 \%$ indicated being biracial. Youth also reported on parent/guardian education: college or a higher level of education (Mothers: 53.9\%; Fathers: 48.7\%), completed some college (Mothers: 23.7\%; Fathers: 20.2\%), or completed high school or below (Mothers: 19.6\%; Fathers: 24.9\%). As a proxy for family financial strain (Galinsky, 1999), youth were asked whether their families had: enough money to buy almost anything they wanted (6.6\%), no problem buying the things they need and can also sometimes buy special things $(49.2 \%)$, just enough money for the things they need $(31.7 \%)$, or a hard time buying the things they need $(12.4 \%)$. Youth ranged in their political beliefs, with $10.7 \%$ identifying as very conservative, $18.3 \%$ identifying as conservative, $19.1 \%$ identifying as moderate, $22.4 \%$ identifying as liberal, $17.4 \%$ identifying as very liberal, and $15.1 \%$ indicating that they did not know their ideology.

We also sampled 778 adults $\left(M_{\text {age }}=38.5, S D=12.5\right.$, Range: 19 to 78 years; $50 \%$ female $)$ through Amazon's Mechanical Turk. Participants were primarily non-Hispanic White (72.1\%), Hispanic or Latinx (11.7\%), Black or African American (11.6\%), Asian (7.1\%), American Indian or Alaska Native (1.4\%), 1.3\% identified as a different race or ethnicity, and $2.2 \%$ indicated being biracial. Adults reported on their highest level of completed education: college or a higher level of education (55.0\%), completed some college $(20.1 \%)$, or completed high school or below (13.9\%). The level of college degree attainment is higher than the national average of $42 \%$ for U.S. adults 25 and older from 2015-2019 (McElrath \& Martin, 2021). Participants' median household income ranged from $\$ 40,000$ to $\$ 59,999$. Adults varied in their political ideology, with $8.5 \%$ identifying as very conservative, $20.2 \%$ identifying as conservative, $25.1 \%$ identifying as moderate, $27.7 \%$ identifying as liberal, $16.7 \%$ identifying as very liberal, and $1.3 \%$ indicating that they did not know their ideology. 
All participants indicated that they were US citizens. Adolescent participants who provided informed assent and adult participants who provided informed consent completed a 5minute survey. This study involved no more than minimal risk and thus, passive parental permission was used for adolescents. Upon survey completion, adolescents were given a link to a letter explaining their participation in the study and asked to provide this letter to their parents. Adolescents who completed the survey were eligible to win a randomly drawn Amazon Gift Card worth $\$ 50$ and adults received $\$ 1$ for their participation. This study was approved by the Institutional Review Board at [blinded for review].

\section{Measures}

Judgements and Justifications for Changing the Voting Age. Participants reported on their judgements about whether the voting age should be changed by responding to a single question that stated, "Should 16 and 17-year-olds be able to vote?". Responses were given on a 3-point nominal scale including 1 (Yes), 2 (Maybe), 3 (No). A follow-up question (Why or why not?) prompted participants to justify their judgments. A coding system was designed to assess the meaning of participants' justifications for changing the voting age and assign specific content codes. Two coders, the first author and a reliability coder, analyzed participants' justifications and assigned a single code to each written statement within a response. Responses that contained multiple statements were assigned a code for each distinct statement. Coders were blinded to participants' age. Kappa coefficients of .70 or higher and were considered adequate (de Vries et al., 2008). Table 1 displays the content coding categories and reliability metrics for participants' justifications about changing the voting age.

Integrative Complexity Coding. The first author and three trained research assistants coded adolescents' and adults' integrative, elaborative, and dialectic complexity of their 
justifications for changing the voting age. Table 2 displays example statements representing low, medium, and high complexity. Coders were trained using the standardized coding manual for integrative complexity (Baker-Brown et al., 1992) and the elaborate and dialectic coding manual (Conway et al., 2008). A practice dataset consisting of 30 responses were used for training prior to coding the full data. Inter-rater reliability was good across ages and categories (ICCs $=.85$ to $.92)$.

\section{Analytic Technique}

Bayesian $t$-tests and regression models were used test study hypotheses. Bayesian analyses were especially suited to test study hypotheses given the ability to quantify evidence of absence (i.e., adolescents and adults are practically similar in their reasoning complexity). Primary analyses occurred in two steps. First, Bayes Factors were estimated for between-person $t$-tests to examine mean differences in integrative, elaborative, and dialectic complexity among 16 and 17-year-olds and adults. Second, three Bayesian regression models were estimated to examine associations between age and integrative, elaborative, and dialectic complexity, after accounting for task-related and individual difference covariates. Each indicator of complexity was specified as the outcome, dichotomous age (16-17 years versus $18+$ years) was specified as the primary independent variable and response word count, support for changing the voting age, and political ideology were specified as covariates. A region of practical equivalence (ROPE) was specified for the posterior distribution as one tenth of a standard deviation of the dependent variable above and below zero (Cohen, 1988). Evidence in support of the alternative or null hypothesis was reflected in Bayes Factors $>|3.0|$ (with very strong evidence indicated by BF $>\mid$ 10 ) or $95 \%$ of the posterior distribution being located above or below the ROPE. Models were 
estimated using 'ggstatsplot' and the 'rstanarm' packages in R. The rstanarm package estimates general linear models using 4 chains and 2,000 iterations as a default specification.

Priors Specification. A default weakly informative Cauchy prior of 0.707 was used for the estimated Bayes Factors. Default weakly informative priors were also used for the Bayesian regressions, which entails applying scaling adjustments to normal priors centered at 0 and with a 2.5 standard deviation. Weakly informative priors are supported by past research suggesting that adolescents and adults are similar in cognitive ability (Steinberg et al., 2009) and were preferred over flat or uninformative priors, which assign an equal probability to values near zero as extreme values.

Planned Robustness Checks. Three robustness checks were planned for this study. First, although weakly informed priors were preferred over uninformative priors due to the unequal likelihood of extreme values, sensitivity analyses were performed by setting priors to be uniform to determine if prior specification altered study inferences. Second, although the purpose of this study is to compare 16 and 17-year-olds reasoning complexity to adults, it is possible that potential age differences in reasoning complexity varies among adults (Salthouse, 2004). Thus, complexity ratings were plotted as a function of continuous age to explore possible differences that arise at specific age groups. Third, to test the generalizability of our effects, sensitivity analyses were conducted to explore if age differences in reasoning complexity varied by political ideology.

Missing Data. Low levels of missing data on demographic covariates $(<5 \%)$ were estimated using multiple imputation and the MICE package. Sensitivity analyses demonstrated that findings were similar in terms of effect size and pattern of significance when using multiple imputation and listwise deletion. 


\section{Results}

\section{Judgements and Justifications about Changing the Voting Age}

Figure 1a displays adolescents' and adults' judgements for whether 16 and 17-year-olds should be able to vote in the US. Overall, $34 \%$ of youth indicated that the voting age should be changed, 33\% indicated that they were unsure, and 33\% indicated that the voting age should not be changed. Adults were less supportive of changing the voting age relative to youth, $\chi(2)=$ $117.21, p<.001$; all adjusted chi-square residuals $>|6.2|$. For adults, $16 \%$ indicated that the voting age should be changed, $18 \%$ were unsure, and $67 \%$ indicated that the voting age should not be changed.

Table 1 and Figure 1b-c present the frequencies of justifications against changing the voting age among those who were unsure or opposed the change for both 16 and 17-year-olds and adults. Consistent with past research (Wray-Lake et al., 2020), justifications against changing the voting age primarily concerned whether 16 and 17-year-olds possessed sufficient political maturity to vote, including beliefs that (1) youth lack sufficient political knowledge to vote (38\% of adolescents; $36 \%$ adults), (2) youth lack the cognitive capacity to vote (23\% of adolescents; $23 \%$ of adults), (3) youth lack the necessary independence to vote (20\% adolescents; $14 \%$ of adults), (4) youth lack the life experience to vote (6\% of adolescents; $15 \%$ of adults), and (5) youth have insufficient political interest and awareness to vote (14\% of adolescents; $6 \%$ of adults). Reliabilities were acceptable for each of these five categories. Justifications supporting changing the voting age included beliefs that (1) adolescents possess a high amount of political knowledge to vote (33\% of adolescents; $13 \%$ adults), (2) that changing the voting is necessary to uphold the social contract (30\% of adolescents; $12 \%$ of adults), (3) that adolescents possess a high degree of developmental maturity (11.7\% adolescents; $6.2 \%$ adults), 
(4) and that allowing youth to vote will benefit democracy (8.3\% adolescents; $3.1 \%$ adults).

Reliabilities were acceptable for each of these four categories.

\section{Age Differences in Complexity of Reasoning}

Table 3 displays the means, standard deviations, and bivariate correlations among study demographics and reasoning complexity. Youth provided longer responses to their justification about changing the voting age, with 16 and 17-year-olds writing approximately 9 more words on average than adults (34 average words compared to 25 average words). Those who indicated that they were unsure whether the voting age should be changed had higher integrative, elaborative, and dialectic complexity in their reasoning relative to those who indicated "yes" or "no". Consistent with previous research (Suedfeld, 2010), identifying more strongly as liberal was associated with higher integrative, elaborative, and dialectic complexity in their reasoning.

Figure 2a-c display mean comparisons of integrative, elaborative, and dialectic complexity for 16 and 17-year-olds versus adults. Bayes Factors indicate very strong evidence that adolescents had higher integrative $\left(\mathrm{BF}_{10}>10\right)$, elaborative $\left(\mathrm{BF}_{10}>10\right)$, and dialectic complexity $\left(\mathrm{BF}_{10}>10\right)$ relative to adults, with the largest age difference being in elaborative complexity. Bayesian regressions were estimated with integrative, elaborative, and dialectic complexity specified as outcomes, age specified as the primary independent variable, and judgement, response word count, and ideology specified as covariates. Table 4 displays model estimates and Figure 2d-f displays posterior distributions for the effects of age on reasoning complexity. After adjusting for word count, issue stance, and political ideology, there was a $97.17 \%$ probability that adolescents had a higher integrative complexity and $2.83 \%$ probability that adolescents had a similar level of integrative complexity compared to adults, with a -0.16 median effect of age. There was a $0 \%$ probability that adults had a higher integrative complexity 
relative to adolescents. Additionally, there was a $100 \%$ probability adolescents had a higher elaborative complexity than adults, with a -0.19 median effect of age. There was a $0 \%$ probability that adults had a similar or higher dialectic complexity relative to adolescents. Further, there was a $17.08 \%$ probability that adolescents had a higher dialectic complexity and $82.78 \%$ probability adolescents had a similar level of dialectic complexity than adults, with a 0.02 median effect of age. There was a $1.30 \%$ probability that adults had a higher dialectic complexity relative to adolescents.

\section{Planned Robustness Checks}

Alternative Priors. Alternative uniform prior distributions were specified to test the robustness of our models and the possible impact of the weakly informative prior specifications on our inferences. Estimates are presented in the Supplemental File. In all analyses, models specifying uniform priors provided similar support for age differences in all three types of reasoning complexity, with adolescents demonstrating more complex reasoning relative to adults.

Continuous Age Trends. A second series of robustness checks examined whether integrative, elaborative, and dialectic complexity varied across the adult years. Figure 3 displays reasoning complexity by continuous age and indicates that the average level of integrative, elaborative, and dialectic complexity is always higher for 16 and 17-year-olds relative to the average level of complexity at all other ages.

Generalizability across Political Ideology. A third series of robustness checks examined whether age differences in integrative, elaborative, and dialectic complexity varied across political ideology. Our primary regression models were re-estimated with an interaction term specified between age and ideology. Full models are presented in the Supplemental File. All 
credibility intervals for the interaction between age and political ideology contained zero, and there was an $86 \%-100 \%$ chance that the interaction coefficient was located within the ROPE across models. Subgroup analyses indicated that adolescents demonstrated higher integrative, elaborative, and dialectic complexity compared to adults across ideology.

\section{Discussion}

Reasoning about political issues is an important marker of the cognitive abilities and is necessary for high-quality political participation. Consistent with past research (Wray-Lake et al., 2020), findings from this study indicate that a primary reason why the general public opposes lowering the voting age concerns beliefs that 16 and 17-year-olds possess insufficient political knowledge and cognitive ability to make informed decisions. A goal of this study was to test age differences and similarities in adolescents' and adults' justifications for whether 16 and 17-yearolds should be able to vote. Contrary to public opinion, but consistent with theory and past research (Conway et al., 2008; Oosterhoff et al., 2021), results indicate that adolescents provide more complex reasoning in their justifications for or against changing the voting age. These findings were consistent after accounting for voting age policy opinions, response length, and political ideology.

Two different cognitive development perspectives could explain our findings. The first perspective concerns past research and theory regarding the age at which adolescents possess adult-like cognitive abilities. Some evidence suggests that beginning at 16 years, adolescents become similar to adults in basic cognitive skills, including working memory and verbal fluency (Steinberg et al., 2009). This research suggests that adolescents are equally equipped for reasoning about political decisions as adults. Findings from this study indicate that adolescents and adults did not meaningfully differ in their dialectical complexity about whether 16 and 17- 
year-olds should be able to vote, which means they showed equal capacity for considering multiple points on both sides of this issue. Both youth and adults who were undecided on the issue showed higher dialectical complexity, suggesting this form of reasoning is heightened when individuals of any age see the issue as ambiguous.

The second perspective concerns the domain-specificity theory of cognitive complexity, which proposes that people provide more complex reasons for beliefs on issues of high personal relevance (Conway et al., 2001). This theory may explain why adolescents provided even greater integrative and elaborative complexity in their reasoning for or against changing the voting age compared to adults. Deciding whether adolescents have the right to vote has greater implications for youth relative to adults, which may have prompted greater critical thinking for adolescents. The domain relevance may stimulate forms of reasoning that are key to articulating views that are already formed, such as abilities to integrate multiple perspectives about an issue (i.e., integrative complexity) and provide multiple reasons to support the same argument (i.e., elaborative complexity). Although we only examined one issue in this study, many other political issues disproportionately affect young people relative to adults, including education policy, environmentalism, gun control and campus carry, the age of being prosecuted as an adult, and abortion laws. Future research should examine age differences in the complexity of reasoning applied to a wider variety of issues that are more and less relevant for young people to test the robustness of domain-specificity theory.

Results from this study offer important contributions to public and policy debates over expanding voting rights for 16 and 17-year-olds. Adolescents were equally equipped to recognize multiple opposing perspectives on an issue that concerns their own rights, and showed higher capacity for integrative and elaborative complexity in reasoning than adults. Even if 
adolescents are better at reasoning about certain issues that affect them, there are numerous such issues, and sophisticated reasoning is certainly advantageous for voting. Furthermore, adults are not required to meet any criteria for complex reasoning capacity in order to be allowed to vote; thus, it might be considered unduly burdensome to require that adolescents' reasoning be as good or better than adults on every single issue before they are allowed the right to vote. Evidence on adolescents' reasoning for any single issue counters public and policymakers' blanket concerns that 16 and 17-year-olds are not developmentally capable of high-quality political participation (Wray-Lake et al., 2020). Overall, findings from this study contribute to a broader mission of using developmental science to inform public policy concerning the rights and responsibilities of adolescents (Oosterhoff et al., 2021; Steinberg \& Icenogle, 2019).

Findings should be interpreted in context of certain limitations and constraints on generalizability. While adolescents and adults were similar in terms of demographic characteristics, both samples were primarily White. Future research is needed to replicate these findings with more racially and ethnically diverse samples. Adolescents and adults were recruited using different online methods (social media and Mechanical Turk). Although we controlled for issue stance and word count in our model, it is possible that other differences between recruitment methods and task motivation of participants may have contributed to differences in our results. It is important to consider that even if youth in this sample were more motivated and engaged in their responses, these differences would still demonstrate that 16 and 17-year-olds are capable of providing more complex reasoning about political issues than adults. An alternative hypothesis for developmental differences in reasoning complexity is cohort effects: today's adolescents may have richer opportunities to learn and practice complex reasoning compared to adolescents of previous generations. Historical data on reasoning 
complexity would be needed to examine possible cohort effects, yet patterns favoring higher complex reasoning among adolescents would still suggest their sufficient cognitive capabilities to vote.

\section{Conclusion}

Developmental scholars have called for the use of developmental science to provide an empirically-informed voting age (Oosterhoff et al., 2021). This study informs this effort by providing evidence the refutes popular opinion regarding the capability of adolescents to meaningfully engage with political issues. Results build on a growing body of evidence that indicates that 16 and 17-year-olds are developmentally prepared to vote (Hart \& Atkins, 2011; Stiers et al., 2020) and highlight the need for the translation of empirical evidence to inform public opinion. 


\section{References}

Baker-Brown, G., Ballard, E. J., Bluck, S., deVries, B., Suedfeld, P., \& Tetlock, P. E. (1992). The conceptual/integrative complexity scoring manual. In C. P. Smith (Ed.), Motivation and personality: Handbook of thematic content analysis (pp. 401-418). Cambridge, UK: Cambridge University Press.

Baltes, P. B. (1987). Theoretical propositions of life-span developmental psychology: On the dynamics between growth and decline. Developmental Psychology, 23(5), 611-626. https://doi.org/10.1037/0012-1649.23.5.611

Campbell, D. E., \& Niemi, R. G. (2016). Testing civics: State-level civic education requirements and political knowledge. American Political Science Review, 110(3), 495-511. https://doi.org/10.1017/S0003055416000368

Chan, T. W., \& Clayton, M. (2006). Should the voting age be lowered to sixteen? Normative and empirical considerations. Political Studies, 54(3), 533-558. https://doi.org/10.1111/j.1467-9248.2006.00620.x

Cohen J. (1988). Statistical Power Analysis for the Behavioral Sciences. New York, NY:

Routledge Academic

Conway, L. G., III, Suedfeld, P., \& Tetlock, P. E. (2001). Integrative complexity and political decisions that lead to war or peace. In D. J. Christie, R. V. Wagner, \& D. Winter (Eds.), Peace, conflict, and violence: Peace psychology for the 21st century (pp. 66-75). Englewood Cliffs, NJ: Prentice-Hall.

Conway III, L. G., Gornick, L. J., Burfeind, C., Mandella, P., Kuenzli, A., Houck, S. C., \& Fullerton, D. T. (2012). Does complex or simple rhetoric win elections? An integrative complexity analysis of u.s. presidential campaigns: complexity and electoral success in 
u.s. presidential campaigns. Political Psychology, 33(5), 599-618. https://doi.org/10.1111/j.1467-9221.2012.00910.x

Conway, L. G., Thoemmes, F., Allison, A. M., Towgood, K. H., Wagner, M. J., Davey, K., Salcido, A., Stovall, A. N., Dodds, D. P., Bongard, K., \& Conway, K. R. (2008). Two ways to be complex and why they matter: Implications for attitude strength and lying. Journal of Personality and Social Psychology, 95(5), 1029-1044. https://doi.org/10.1037/a0013336

De Vries, H., Elliott, M. N., Kanouse, D. E., \& Teleki, S. S. (2008). Using pooled kappa to summarize interrater agreement across many items. Field Methods, 20(3), 272-282. https://doi.org/10.1177/1525822X08317166

Fabina, J. (2021). Despite pandemic challenges, 2020 election had largest increase in voting between presidential elections on record. Retrieved from: https://www.census.gov/library/stories/2021/04/record-high-turnout-in-2020-generalelection.html

Hannity, S. (2019). Pelosi's plot revealed: Nancy says lowering voting age to 16 is necessary to 'Capture the Kids'. Retrieved from: https://hannity.com/media-room/pelosis-plotrevealed-nancy-says-lowering-voting-age-to-16-is-necessary-to-capture-the-kids/.

Hart, D., \& Atkins, R. (2011). American sixteen- and seventeen-year-olds are ready to vote. The ANNALS of the American Academy of Political and Social Science, 633(1), 201-222. https://doi.org/10.1177/0002716210382395

Hart, D., \& Youniss, J. (2018). Renewing Democracy in Young America. Oxford University Press. 
Kahne, J., \& Bowyer, B. (2017). Educating for democracy in a partisan age: Confronting the challenges of motivated reasoning and misinformation. American Educational Research Journal, 54(1), 3-34. https://doi.org/10.3102/0002831216679817

Lee, H. F., Gorsuch, R. L., Saklofske, D. H., \& Patterson, C. A. (2008). Cognitive differences for ages 16 to 89 years (canadian wais-iii): Curvilinear with flynn and processing speed corrections. Journal of Psychoeducational Assessment, 26(4), 382-394. https://doi.org/10.1177/0734282908323628

McElrath, K., Martin, M. (2021). Bachelor's Degree Attainment in the United States: 2005 to 2019. (ACSBR-009). US Census Bureau. https://www.census.gov/content/dam/Census/library/publications/2021/acs/acsbr-009.pdf

Oosterhoff, B., Wray-Lake, L., \& Hart, D. (2021). Reconsidering the minimum voting age in the United States. Perspectives in Psychological Science.

Steinberg, L., Cauffman, E., Woolard, J., Graham, S., \& Banich, M. (2009). Are adolescents less mature than adults?: Minors' access to abortion, the juvenile death penalty, and the alleged APA “flip-flop.” American Psychologist, 64(7), 583-594. https://doi.org/10.1037/a0014763

Steinberg, L., \& Icenogle, G. (2019). Using developmental science to distinguish adolescents and adults under the law. Annual Review of Developmental Psychology, 1(1), 21-40. https://doi.org/10.1146/annurev-devpsych-121318-085105

Stiers, D., Hooghe, M., \& Goubin, S. (2020). Are 16-year-olds able to cast a congruent vote? Evidence from a "voting at 16" initiative in the city of ghent (belgium). Electoral Studies, 63, 102107. https://doi.org/10.1016/j.electstud.2019.102107 
Wagner, M., Johann, D., \& Kritzinger, S. (2012). Voting at 16: Turnout and the quality of vote choice. Electoral Studies, 31(2), 372-383. https://doi.org/10.1016/j.electstud.2012.01.007

Wray-Lake, L., Wilf, S., \& Oosterhoff, B. (2020). Reconsidering the voting age in Los Angeles and California. In D.J.B. Mitchell (Ed.), California Policy Options 2020. Los Angeles: UCLA School of Public Affairs. 
Table 1

Coding Categories and Examples of Justifications for and against Changing the Voting Age.

\begin{tabular}{|c|c|c|c|c|c|}
\hline & Example Statement & $\begin{array}{c}\text { Kappa } \\
\text { (Teen/Adult) }\end{array}$ & $\begin{array}{l}\text { Total } \\
\text { N }(\%)\end{array}$ & $\begin{array}{c}\text { 16-17 Y.O. } \\
\text { N (\%) }\end{array}$ & $\begin{array}{l}\text { Adults } \\
\text { N }(\%)\end{array}$ \\
\hline \multicolumn{6}{|c|}{ Categories Opposing Changing the Voting Age } \\
\hline Lack Political Knowledge & $\begin{array}{l}\text { Teen: "I don't think we are educated enough to understand what our } \\
\text { vote means and how we are impacting the country." } \\
\text { Adult: "Most } 16 \text { and } 17 \text {-year-olds aren't aware of enough of the } \\
\text { important political decisions that need to be made." }\end{array}$ & $.92 / .85$ & $303(25.8)$ & $89(21.7)$ & $214(27.2)$ \\
\hline Lack Cognitive Capacity & $\begin{array}{l}\text { Teen: "The human brain isn't developed enough to vote, even at 18." } \\
\text { Adult: "Their brains are not mature yet" }\end{array}$ & $.91 / .90$ & $232(19.7)$ & $68(16.6)$ & $164(21.0)$ \\
\hline Lack Political Independence & $\begin{array}{l}\text { Teen: "We are easily affected by peer pressure." } \\
\text { Adult: "They will do what their parents do" }\end{array}$ & $.79 / .83$ & $161(13.7)$ & $60(14.7)$ & $101(12.9)$ \\
\hline Lack Political Interest & $\begin{array}{l}\text { Teen: "Most teens in these days don't bother with politics" } \\
\text { Adult: "Too young to care" }\end{array}$ & $.80 / .82$ & $78(6.6)$ & $40(9.8)$ & $38(4.8)$ \\
\hline Lack Life Experience & $\begin{array}{l}\text { Teen: "Not enough life experience to really understand the choice } \\
\text { they are making." } \\
\text { Adult: "I think that } 16 \text { and } 17 \text { year olds need a little more real } \\
\text { world experience before they should be allowed to vote." }\end{array}$ & $.84 / .86$ & $112(9.5)$ & $15(3.7)$ & $97(12.4)$ \\
\hline \multicolumn{6}{|c|}{ Categories Supporting Changing the Voting Age } \\
\hline High Political Knowledge & $\begin{array}{l}\text { Teen: "Many } 16 \text { and } 17 \text {-year-olds are more politically informed than } \\
\text { actual eligible voters." } \\
\text { Adult: "Probably more informed than a lot of the electorate" }\end{array}$ & $.83 / .91$ & $239(20.3)$ & $134(32.7)$ & $105(13.3)$ \\
\hline High Developmental Maturity & $\begin{array}{l}\text { Teen: "I believe we are at an age where we can make solid choices." } \\
\text { Adult: "I think } 16 \text { year olds are capable of making important } \\
\text { decisions" }\end{array}$ & $.75 / .78$ & $96(8.2)$ & $48(11.7)$ & $48(6.2)$ \\
\hline Uphold Social Contract & $\begin{array}{l}\text { Teen: "We deserve to have our voices heard because the problems } \\
\text { affect us too." } \\
\text { Adult: "They're affected by the policies being implemented" }\end{array}$ & $.85 / .80$ & $223(19.0)$ & $127(30.1)$ & $96(12.2)$ \\
\hline Benefit Democracy & $\begin{array}{l}\text { Teen: "Since voter turnout is low, having } 16 \text { and } 17 \text {-year-olds vote } \\
\text { will bring it up. It'll help people become more involved in politics and } \\
\text { their community." } \\
\text { Adult: "If teenagers could vote, US citizens would take more of an } \\
\text { interest in politics at an early age." }\end{array}$ & $.74 / .82$ & $58(4.9)$ & $34(8.3)$ & $24(3.1)$ \\
\hline
\end{tabular}

Notes: Percentages are relative to the total sample (Adults $=778 ; 16$ and 17-Year-Olds $=397$ ). Y.O. $=$ Year Old 
Table 2

Example Statements from Adolescents who Support Changing the Vote Age by High, Medium, and Low Complexity.

\begin{tabular}{|c|c|c|c|}
\hline & High (scored 3) & Medium (scored 2) & Low (scored 1) \\
\hline $\begin{array}{l}\text { Integrative } \\
\text { Complexity }\end{array}$ & $\begin{array}{l}\text { "Once you are } 16, \text { you are able to work. Many companies hire at } 16 \text {, } \\
\text { you can drive at } 16 \text {, you could drop out of school at } 16 \text {. This means } \\
\text { that many laws that did not affect you before will now affect you. } \\
\text { However, if we give } 16 \text {-year-olds the right to vote, we need to also } \\
\text { give them information about politics and the government." }\end{array}$ & $\begin{array}{l}\text { "We are certainly impacted by these } \\
\text { laws, and many } 16 \text { and } 17 \text { year olds } \\
\text { are more politically informed than } \\
\text { actual eligible voters" }\end{array}$ & $\begin{array}{l}\text { "We should because we are } \\
\text { made to figure a view point of } \\
\text { the politics but not allowed to } \\
\text { speak out word or vote on } \\
\text { anything" }\end{array}$ \\
\hline $\begin{array}{l}\text { Elaborative } \\
\text { Complexity }\end{array}$ & $\begin{array}{l}\text { "We know just as much about the candidates and how they will affect } \\
\text { our future as any adult. most of us don't live on our own, pay taxes, etc } \\
\text { etc (whatever excuse an adult will say for no), but we do understand } \\
\text { that whosever in office will affect us for the rest of our lives, and that } \\
\text { we need a say" }\end{array}$ & $\begin{array}{l}\text { "Were the ones who have to live } \\
\text { with the laws being created and our } \\
\text { voice needs to be heard just as } \\
\text { much as the others" }\end{array}$ & $\begin{array}{l}\text { "Because we should have a } \\
\text { voice too" }\end{array}$ \\
\hline $\begin{array}{l}\text { Dialectic } \\
\text { Complexity }\end{array}$ & $\begin{array}{l}\text { "I think there are a lot of } 16 \text { and } 17 \text { year olds with defined political } \\
\text { views and ideas that deserve to be recognized and taken seriously. } \\
\text { We're treated as dumb little kids when we have opinions that matter } \\
\text { too. Of course there are some teenagers who wouldn't take voting } \\
\text { seriously or who don't have ideals that a lot of people would agree } \\
\text { with. But what exactly makes you any more ready to vote the moment } \\
\text { you turn eighteen? Where do you draw that line? There are some } \\
\text { people who mature well before their time and some people who stay } \\
\text { immature and childish well into adulthood." }\end{array}$ & $\begin{array}{l}\text { "I'm not sure because although I'm } \\
\text { confident I should be able to vote } \\
\text { and my friends should too, I don't } \\
\text { know enough about other people to } \\
\text { voucher for them as well." }\end{array}$ & $\begin{array}{l}\text { "I think } 16 \text { and } 17 \text { year olds } \\
\text { are mostly capable of making } \\
\text { decisions upon presidency. We } \\
\text { are the future generation." }\end{array}$ \\
\hline
\end{tabular}

Notes: Complexity scores range from 1-7. All quotes are from the adolescent sample. 
Table 3

Means, Standard Deviations, and Bivariate Correlations among Study Variables.

\begin{tabular}{|c|c|c|c|c|c|c|c|c|}
\hline Variable & $M$ & $S D$ & 1 & 2 & 3 & 4 & 5 & 6 \\
\hline 1. Vote & 2.34 & 0.81 & & & & & & \\
\hline 2. Word Count & 27.62 & 25.94 & $-.08 * *$ & & & & & \\
\hline 3. Ideology & 3.30 & 1.19 & $-.33 * *$ & $.09 * *$ & & & & \\
\hline 4. Age & 1.66 & 0.48 & $.29 * *$ & $-.14 * *$ & -.05 & & & \\
\hline 5. Integrative Complexity & 1.59 & 0.73 & $-.07 *$ & $.48 * *$ & $.06 *$ & $-.18 * *$ & & \\
\hline 6. Elaborative Complexity & 1.48 & 0.60 & -.05 & $.47 * *$ & .03 & $-.20 * *$ & $.85 * *$ & \\
\hline 7. Dialectic Complexity & 1.13 & 0.51 & -.04 & $.36 * *$ & $.07 *$ & $-.10 * *$ & $.72 * *$ & $.39 * *$ \\
\hline
\end{tabular}

Notes: Vote is coded 1 = No (oppose change), 2 = Maybe (undecided), $3=$ Yes (support change). Age is coded $1=16-17$ year old, $2=19+$ year old. 


\section{Table 4}

Bayesian Regression Estimates Predicting Reasoning Complexity.

\begin{tabular}{|c|c|c|c|c|c|c|c|c|c|c|c|c|c|c|c|}
\hline \multirow[b]{3}{*}{ (Intercept) } & \multicolumn{5}{|c|}{ Integrative Complexity } & \multicolumn{5}{|c|}{ Elaborative Complexity } & \multicolumn{5}{|c|}{ Dialectic Complexity } \\
\hline & \multirow{2}{*}{$\frac{\text { Median }}{1.41}$} & \multicolumn{2}{|c|}{$95 \% \mathrm{CI}$} & \multirow{2}{*}{$\frac{\% \text { Direction }}{1.00}$} & \multirow{2}{*}{$\frac{\text { ROPE } \%}{0.00}$} & \multirow{2}{*}{$\frac{\text { Median }}{1.53}$} & \multicolumn{2}{|c|}{$95 \% \mathrm{CI}$} & \multirow{2}{*}{$\frac{\% \text { Direction }}{1.00}$} & \multirow{2}{*}{$\frac{\text { ROPE \% }}{0.00}$} & \multirow{2}{*}{$\frac{\text { Median }}{0.83}$} & \multicolumn{2}{|c|}{$95 \% \mathrm{CI}$} & \multirow{2}{*}{$\frac{\% \text { Direction }}{1.00}$} & \multirow{2}{*}{$\frac{\text { ROPE \% }}{0.00}$} \\
\hline & & 1.21 & 1.63 & & & & 1.35 & 1.69 & & & & 0.69 & 0.97 & & \\
\hline Vote: Maybe & 0.25 & 0.13 & 0.36 & 1.00 & 0.00 & -0.08 & -0.18 & 0.01 & 0.95 & 0.33 & 0.39 & 0.31 & 0.47 & 1.00 & 0.00 \\
\hline Vote: No & 0.05 & -0.06 & 0.16 & 0.81 & 0.66 & 0.02 & -0.07 & 0.10 & 0.64 & 0.79 & 0.08 & 0.00 & 0.15 & 0.97 & 0.27 \\
\hline Word Count & 0.01 & 0.01 & 0.01 & 1.00 & 1.00 & 0.01 & 0.01 & 0.01 & 1.00 & 1.00 & 0.01 & 0.01 & 0.01 & 1.00 & 1.00 \\
\hline Ideology & 0.01 & -0.03 & 0.04 & 0.63 & 1.00 & 0.00 & -0.03 & 0.03 & 0.50 & 1.00 & 0.01 & -0.02 & 0.03 & 0.76 & 1.00 \\
\hline Age & -0.16 & -0.24 & -0.07 & 1.00 & 0.03 & -0.19 & -0.27 & -0.12 & 1.00 & 0.00 & -0.02 & -0.08 & 0.04 & 0.74 & 0.83 \\
\hline
\end{tabular}

Notes: $\mathrm{CI}=$ Credibility Interval. ROPE \% calculated based on distribution. 
A

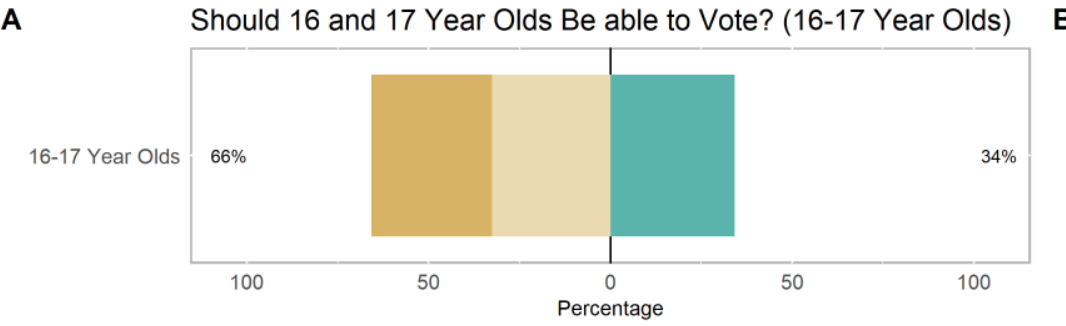

Yes Maybe $\mathbf{1}$ No

C

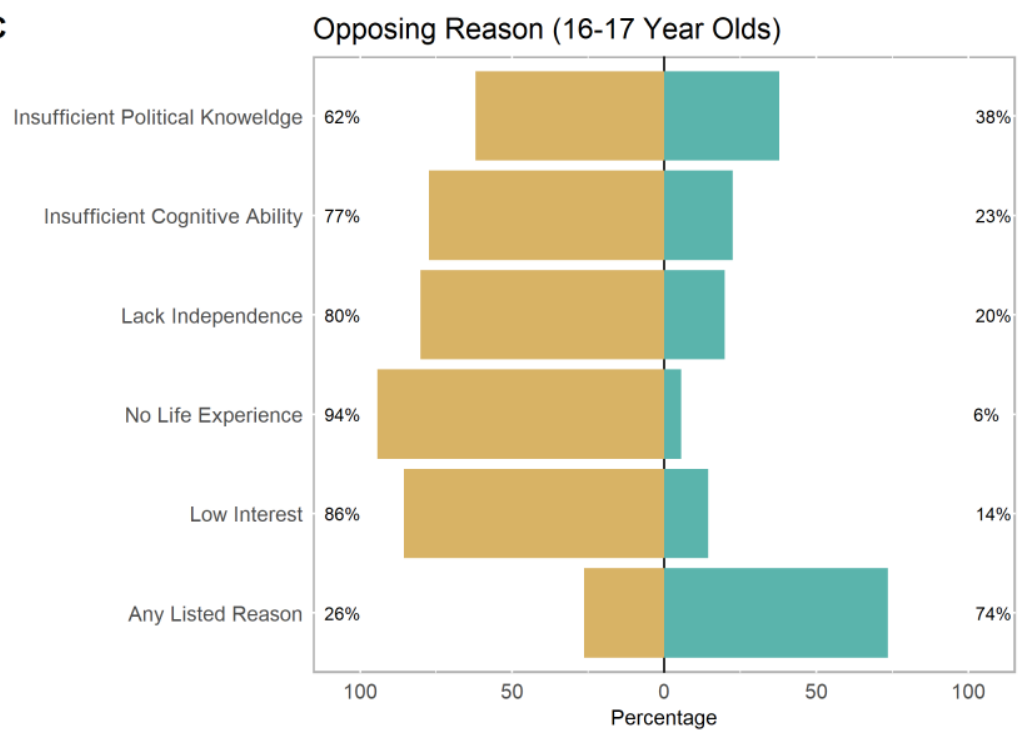

Reason not given $\square$ Given unprompted reason
Should 16 and 17 Year Olds Be able to Vote? (Adults)

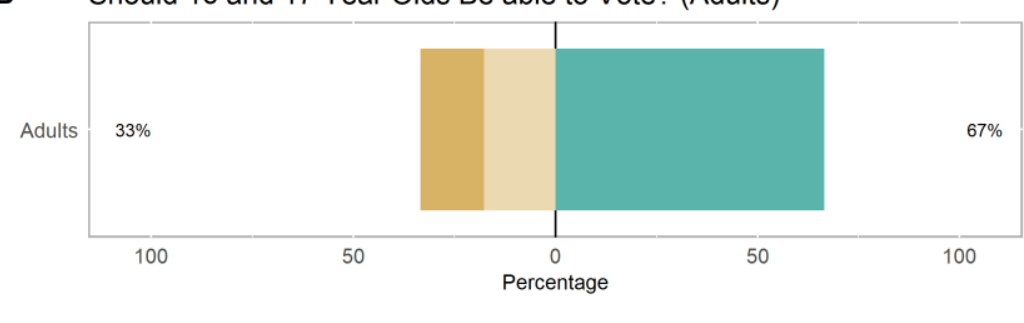

D

Yes Maybe $\amalg \mathrm{No}$

Opposing Reason (Adults)

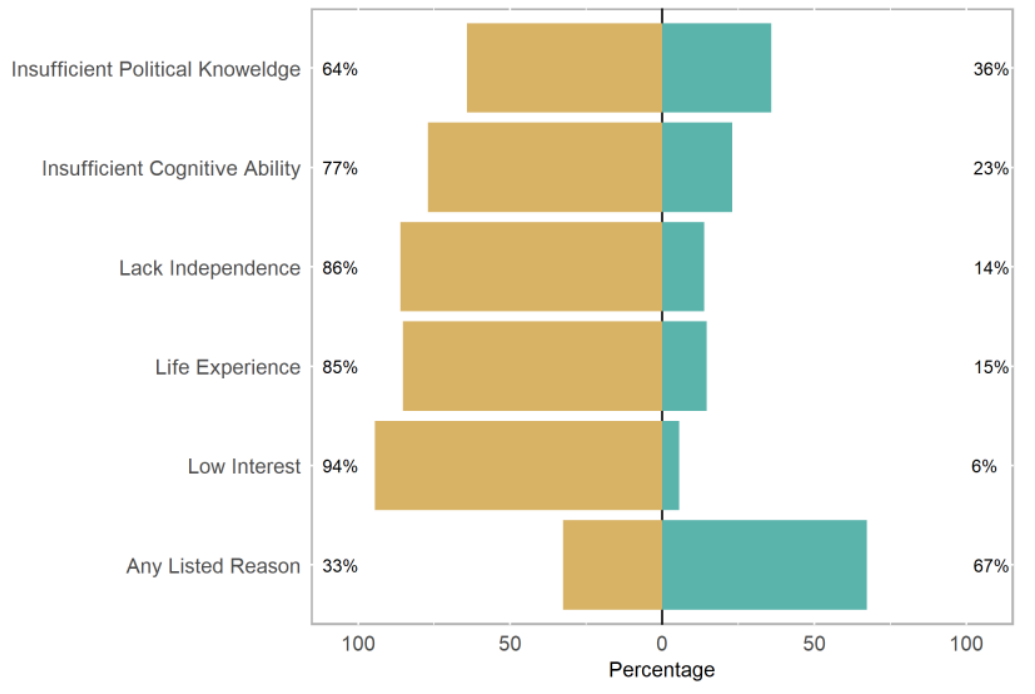

Reason not given ${ }^{1}$ Given unprompted reason

Figure 1. Frequencies of voting age judgements and justifications. Figure 1a: 16-17 year-olds judgments about changing the voting age. Figure 1b: Adults judgments about changing the voting age. Figure 1c: Adolescents' justifications for changing the voting age among those who opposed (indicated "maybe" or "no"). Figure 1d: Adults justifications for changing the voting age among those who opposed (indicated "maybe" or "no"). 
A Integrative Complexity by Age

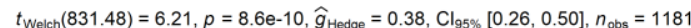

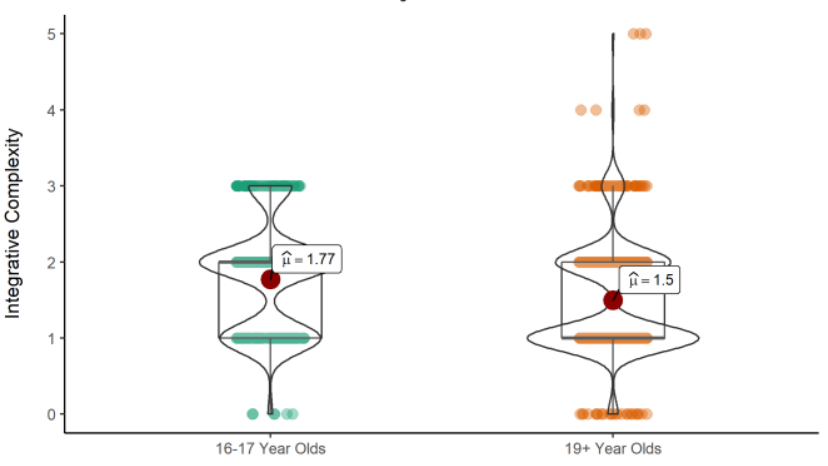

Age

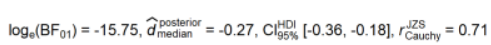

D Posterior Distribution for Effects of Age on Integrative Complexity

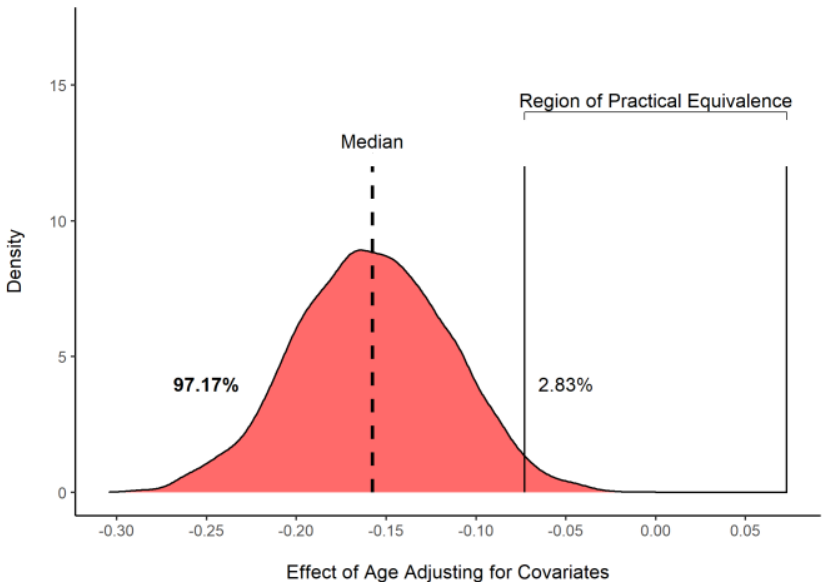

B

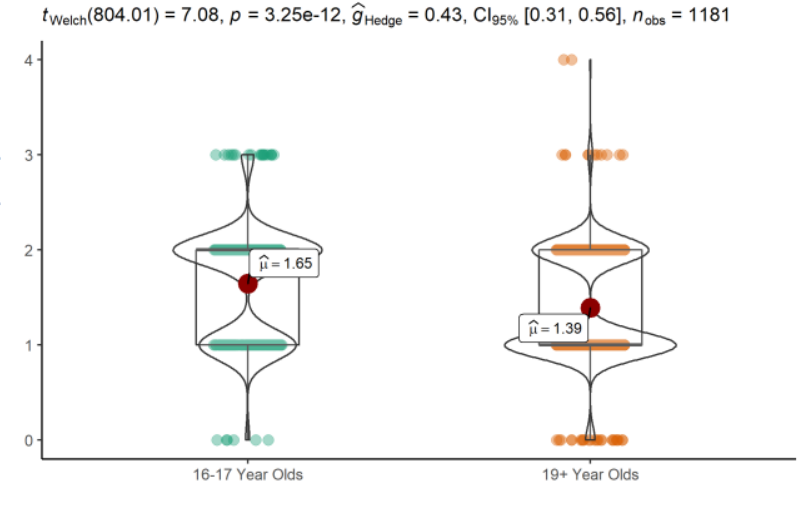

Age

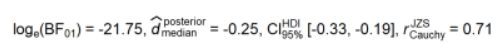

E

Posterior Distribution for Effects of Age on Elaborative Complexity

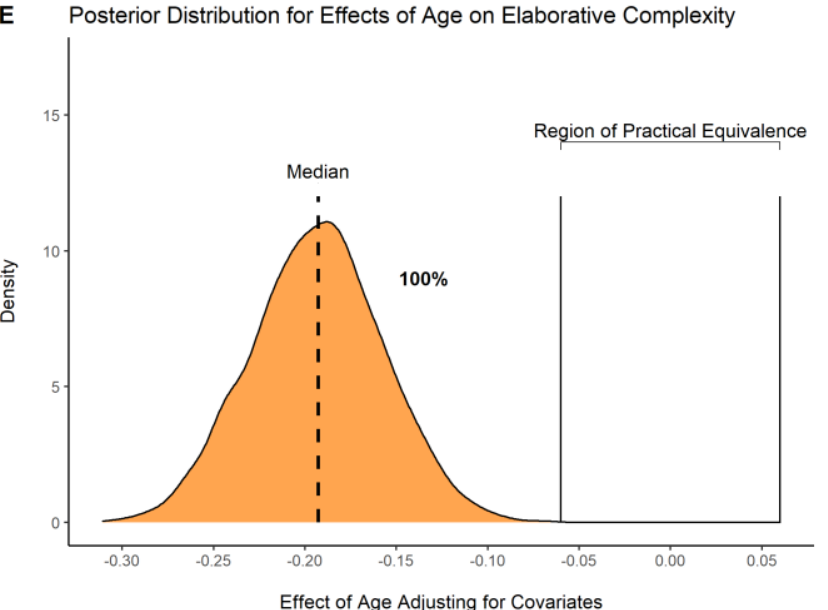

C Dialectic Complexity by Age

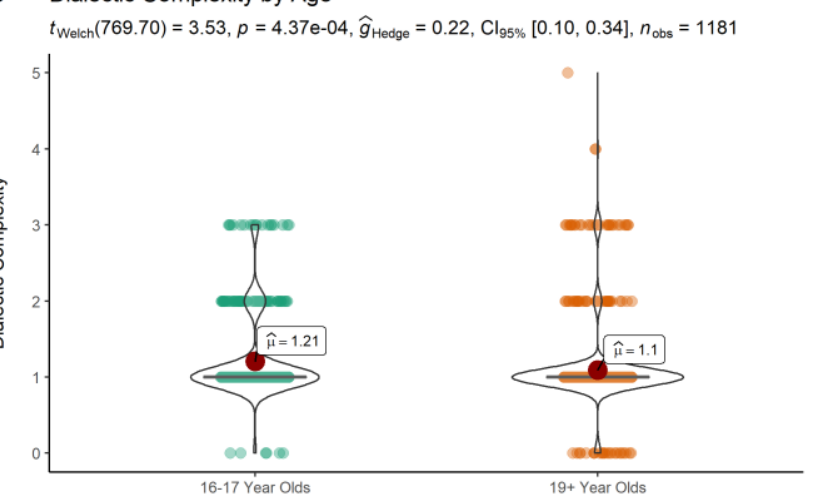

Age

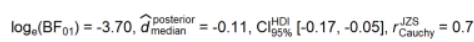

F Posterior Distribution for Effects of Age on Dialectic Complexity

Region of Practical Equivalence
Region of Practical Equivalence

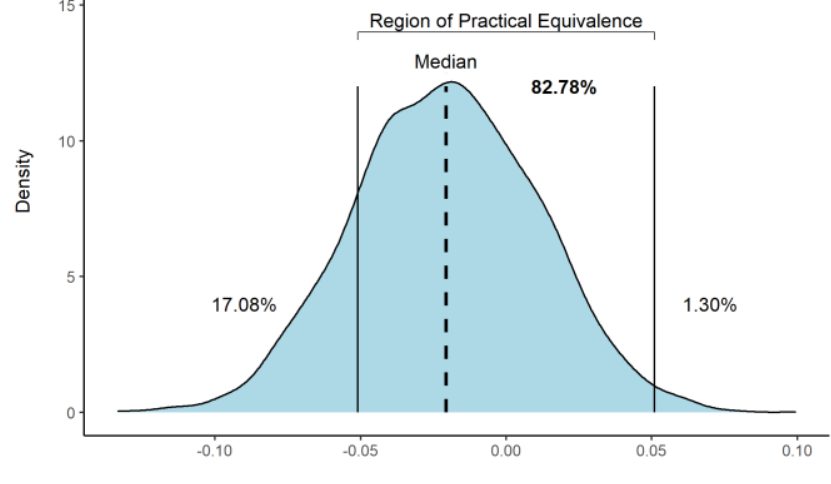

Figure 2. Effects of age on complexity of reasoning for changing the voting age. Figure 2a: Unadjusted mean differences in integrative complexity. Figure 2b: Unadjusted mean differences in elaborative complexity. Figure 2c: Unadjusted mean differences in dialectic complexity. Figure 2d: Effects of age on integrative complexity adjusting for judgments, wordcount, and ideology. Figure 2e: Effects of age on elaborative complexity adjusting for judgments, wordcount, and ideology. Figure 2e: Effects of age on dialectic complexity adjusting for judgments, word count, and ideology.

Notes: For Figure1a-c, blue and orange dots represent individual data points and red dots represent means. 
A Integrative Complexity by Continuous Age

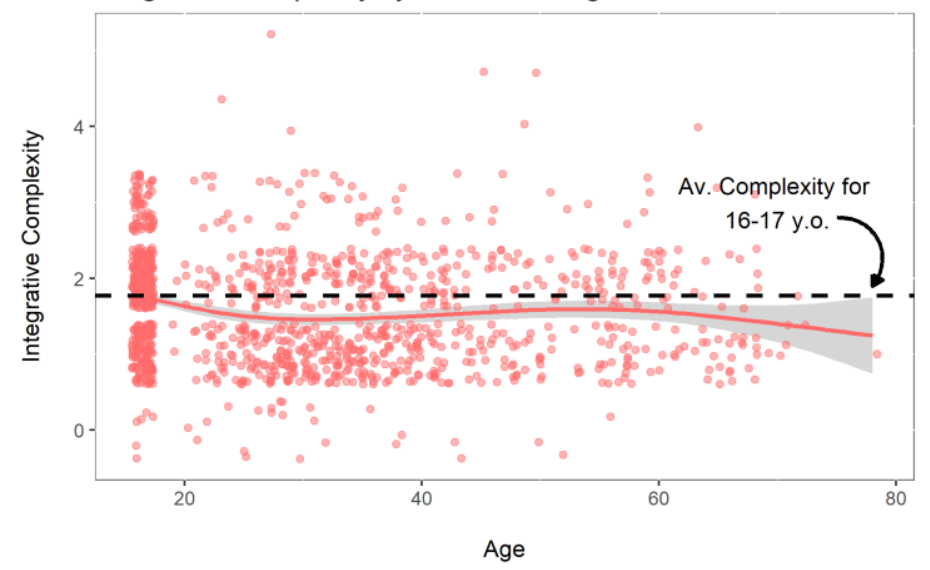

B Ellaborative Complexity by Continuous Age

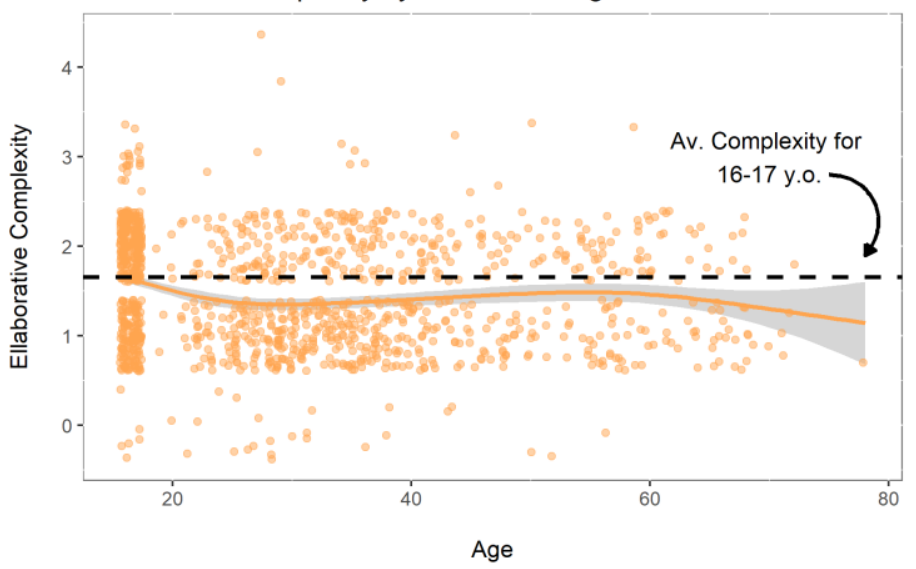

C Dialectic Complexity by Continuous Age

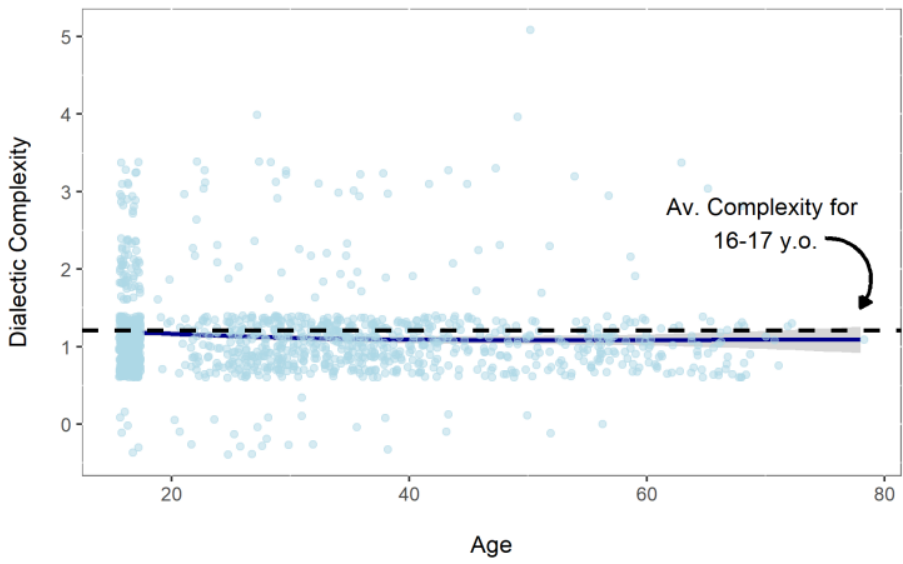

Figure 3. Reasoning complexity by continuous age. Figure 3a: Integrative complexity by continuous age. Figure 3b: Elaborative complexity by continuous age. Figure 1c: Dialectic complexity by continuous age. 


\section{Supplemental File}

Table S1: Robustness Checks: Uninformative Priors

Table S2: Robustness Checks: Ideology Interactions

Figure S1: Age differences in Integrative Complexity by Ideology

Figure S2: Age differences in Elaborative Complexity by Ideology

Figure S3: Age differences in Dialectic Complexity by Ideology 


\section{Robustness Checks: Uninformative Priors}

\begin{tabular}{|c|c|c|c|c|c|c|c|c|c|c|c|c|c|c|c|}
\hline \multirow[b]{3}{*}{ (Intercept) } & \multicolumn{5}{|c|}{ Integrative Complexity } & \multicolumn{5}{|c|}{ Elaborative Complexity } & \multicolumn{5}{|c|}{ Dialectic Complexity } \\
\hline & \multirow{2}{*}{$\begin{array}{l}\text { Median } \\
1.35\end{array}$} & \multicolumn{2}{|c|}{$95 \% \mathrm{CI}$} & \multirow{2}{*}{$\begin{array}{c}\% \\
\text { Direction } \\
1.00\end{array}$} & \multirow{2}{*}{$\begin{array}{c}\text { ROPE } \\
\%\end{array}$} & \multirow{2}{*}{$\begin{array}{l}\text { Median } \\
1.49\end{array}$} & \multicolumn{2}{|c|}{$95 \% \mathrm{CI}$} & \multirow{2}{*}{$\begin{array}{c}\% \\
\text { Direction } \\
1.00\end{array}$} & \multirow{2}{*}{$\frac{\begin{array}{c}\text { ROPE } \\
\%\end{array}}{0.00}$} & \multirow{2}{*}{$\begin{array}{l}\text { Median } \\
0.80\end{array}$} & \multicolumn{2}{|c|}{$95 \% \mathrm{CI}$} & \multirow{2}{*}{$\begin{array}{c}\% \\
\text { Direction } \\
1.00\end{array}$} & \multirow{2}{*}{$\begin{array}{c}\begin{array}{c}\text { ROPE } \\
\%\end{array} \\
0.00\end{array}$} \\
\hline & & 1.19 & 1.53 & & & & 1.35 & 1.63 & & & & 0.69 & 0.92 & & \\
\hline $\begin{array}{l}\text { Vote: } \\
\text { Maybe }\end{array}$ & 0.25 & 0.17 & 0.36 & 1.00 & 0.00 & -0.07 & -0.15 & 0.01 & 0.92 & 0.39 & 0.40 & 0.33 & 0.47 & 1.00 & 0.00 \\
\hline Vote: No & 0.05 & -0.04 & 0.13 & 0.83 & 0.67 & 0.02 & -0.05 & 0.09 & 0.67 & 0.84 & 0.09 & 0.03 & 0.15 & 0.99 & 0.14 \\
\hline $\begin{array}{l}\text { Word } \\
\text { Count }\end{array}$ & 0.01 & 0.01 & 0.01 & 1.00 & 1.00 & 0.01 & 0.01 & 0.01 & 1.00 & 1.00 & 0.01 & 0.01 & 0.01 & 1.00 & 1.00 \\
\hline Ideology & 0.01 & -0.01 & 0.04 & 0.75 & 1.00 & 0.00 & -0.02 & 0.03 & 0.60 & 1.00 & 0.01 & -0.01 & 0.03 & 0.85 & 1.00 \\
\hline Age & -0.15 & -0.22 & -0.07 & 1.00 & 0.05 & -0.19 & -0.24 & -0.12 & 1.00 & 0.00 & -0.02 & -0.08 & 0.03 & 0.72 & 0.87 \\
\hline
\end{tabular}

Notes: $\mathrm{CI}=$ Credibility Interval. ROPE \% calculated based on distribution. 


\section{Robustness Checks: Ideology Interactions}

\begin{tabular}{|c|c|c|c|c|c|c|c|c|c|c|c|c|c|c|c|}
\hline \multirow[b]{3}{*}{ (Intercept) } & \multicolumn{5}{|c|}{ Integrative Complexity } & \multicolumn{5}{|c|}{ Elaborative Complexity } & \multicolumn{5}{|c|}{ Dialectic Complexity } \\
\hline & \multirow{2}{*}{$\begin{array}{l}\text { Median } \\
1.24\end{array}$} & \multicolumn{2}{|c|}{$95 \% \mathrm{CI}$} & \multirow{2}{*}{$\begin{array}{c}\% \\
\text { Direction } \\
1.00\end{array}$} & \multirow{2}{*}{$\begin{array}{c}\begin{array}{c}\text { ROPE } \\
\%\end{array} \\
0.00\end{array}$} & \multirow{2}{*}{$\begin{array}{l}\text { Median } \\
1.49\end{array}$} & \multicolumn{2}{|c|}{$95 \% \mathrm{CI}$} & \multirow{2}{*}{$\begin{array}{c}\% \\
\text { Direction } \\
1.00\end{array}$} & \multirow{2}{*}{$\begin{array}{c}\text { ROPE } \\
\%\end{array}$} & \multirow{2}{*}{$\begin{array}{l}\text { Median } \\
0.64\end{array}$} & \multicolumn{2}{|c|}{$95 \%$ CI } & \multirow{2}{*}{$\begin{array}{c}\% \\
\text { Direction } \\
1.00\end{array}$} & \multirow{2}{*}{$\begin{array}{c}\text { ROPE } \\
\%\end{array}$} \\
\hline & & 0.87 & 1.64 & & & & 1.16 & 1.80 & & & & 0.36 & 0.93 & & \\
\hline Vote: Maybe & 0.25 & 0.16 & 0.35 & 1.00 & 0.00 & -0.07 & -0.15 & 0.00 & 0.94 & 0.37 & 0.41 & 0.34 & 0.47 & 1.00 & 0.00 \\
\hline Vote: No & 0.05 & -0.04 & 0.14 & 0.82 & 0.64 & 0.02 & -0.06 & 0.08 & 0.65 & 0.88 & 0.09 & 0.03 & 0.15 & 0.99 & 0.12 \\
\hline Word Count & 0.01 & 0.01 & 0.01 & 1.00 & 1.00 & 0.01 & 0.01 & 0.01 & 1.00 & 1.00 & 0.01 & 0.01 & 0.01 & 1.00 & 1.00 \\
\hline Ideology & 0.04 & -0.07 & 0.15 & 0.74 & 0.62 & 0.00 & -0.09 & 0.09 & 0.52 & 0.81 & 0.06 & -0.02 & 0.14 & 0.88 & 0.40 \\
\hline Age & -0.08 & -0.29 & 0.12 & 0.74 & 0.36 & -0.19 & -0.37 & -0.03 & 0.96 & 0.06 & 0.07 & -0.09 & 0.22 & 0.77 & 0.35 \\
\hline Age*Ideology & -0.02 & -0.08 & 0.04 & 0.68 & 0.93 & 0.00 & -0.05 & 0.05 & 0.51 & 1.00 & -0.03 & -0.07 & 0.02 & 0.83 & 0.86 \\
\hline
\end{tabular}


Figure S1: Age differences in Integrative Complexity by Ideology
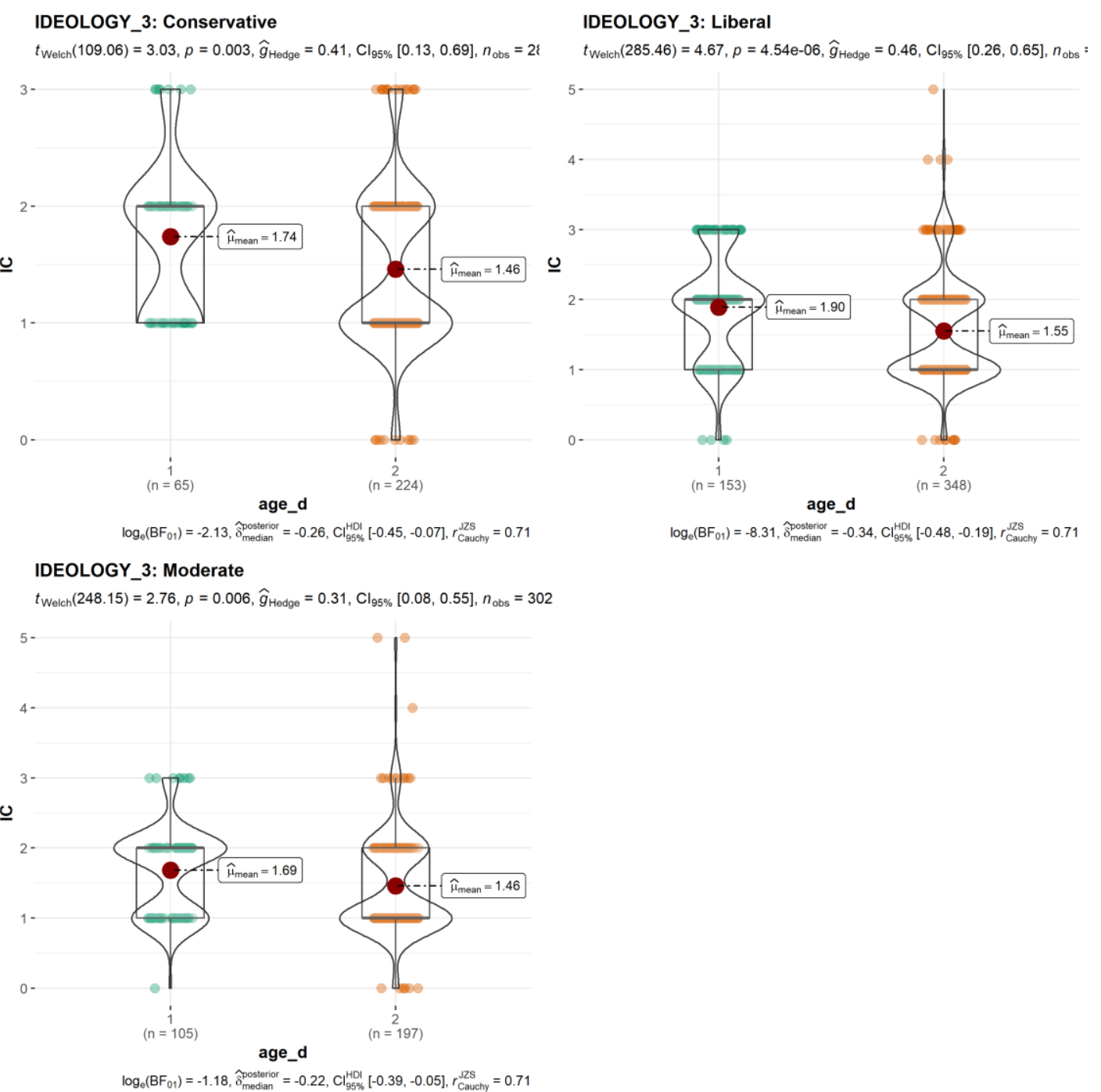
ADOLESCENT REASONING

33

Figure S2: Age differences in Elaborative Complexity by Ideology

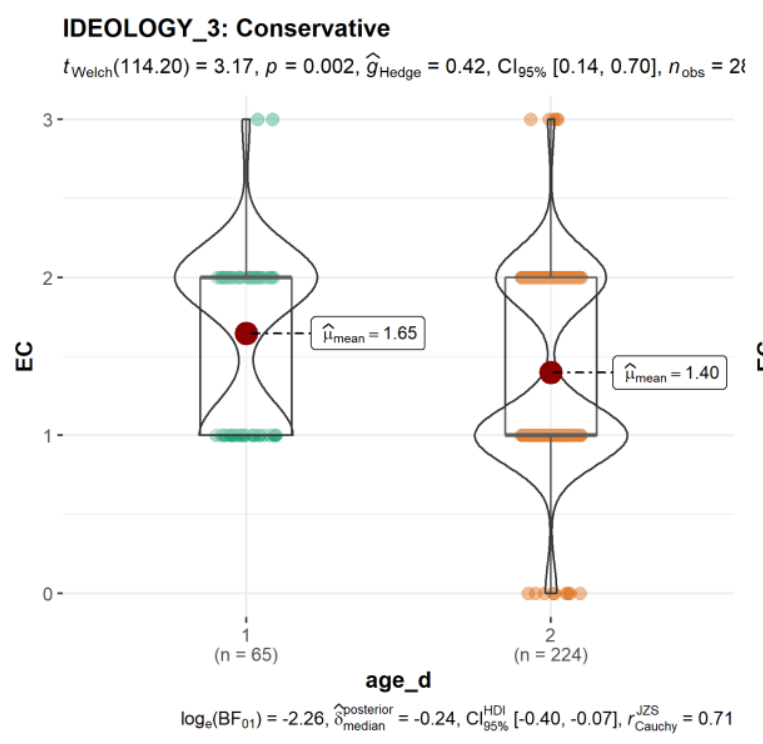

IDEOLOGY_3: Liberal

$t_{\text {Welsh }}(277.56)=5.00, p=1.01 \mathrm{e}-06, \widehat{g}_{\text {Hedge }}=0.49, \mathrm{Cl}_{95 \%}[0.30,0.69], n_{\text {obs }}$ :

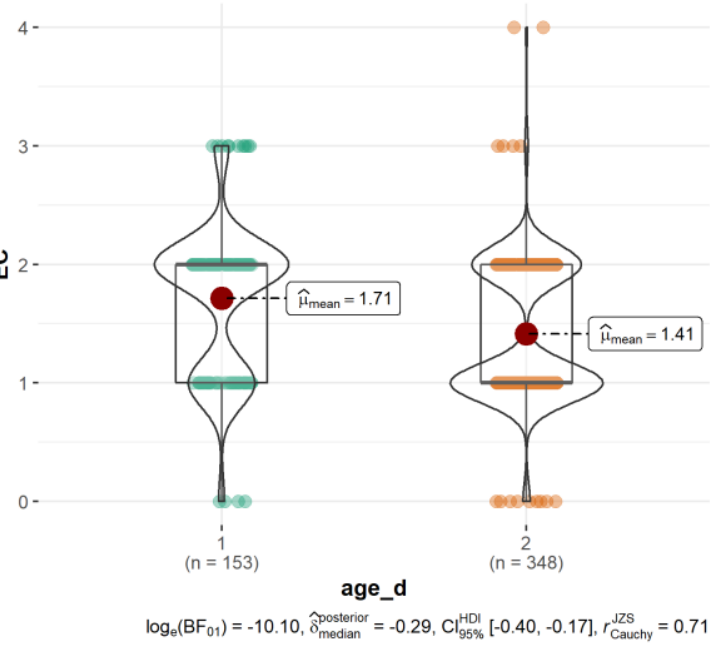

IDEOLOGY _3: Moderate

$t_{\text {Welsh }}(216.17)=3.90, p=1.27 \mathrm{e}-04, \widehat{g}_{\text {Hedge }}=0.47, \mathrm{Cl}_{95 \%}[0.23,0.71], n_{\text {obs }}=302$

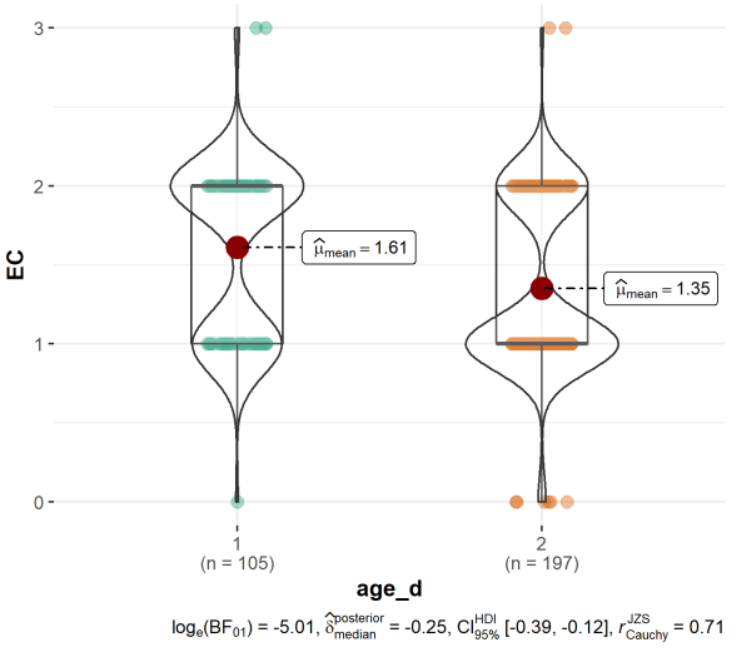


Figure S3: Age differences in Integrative Complexity by Ideology
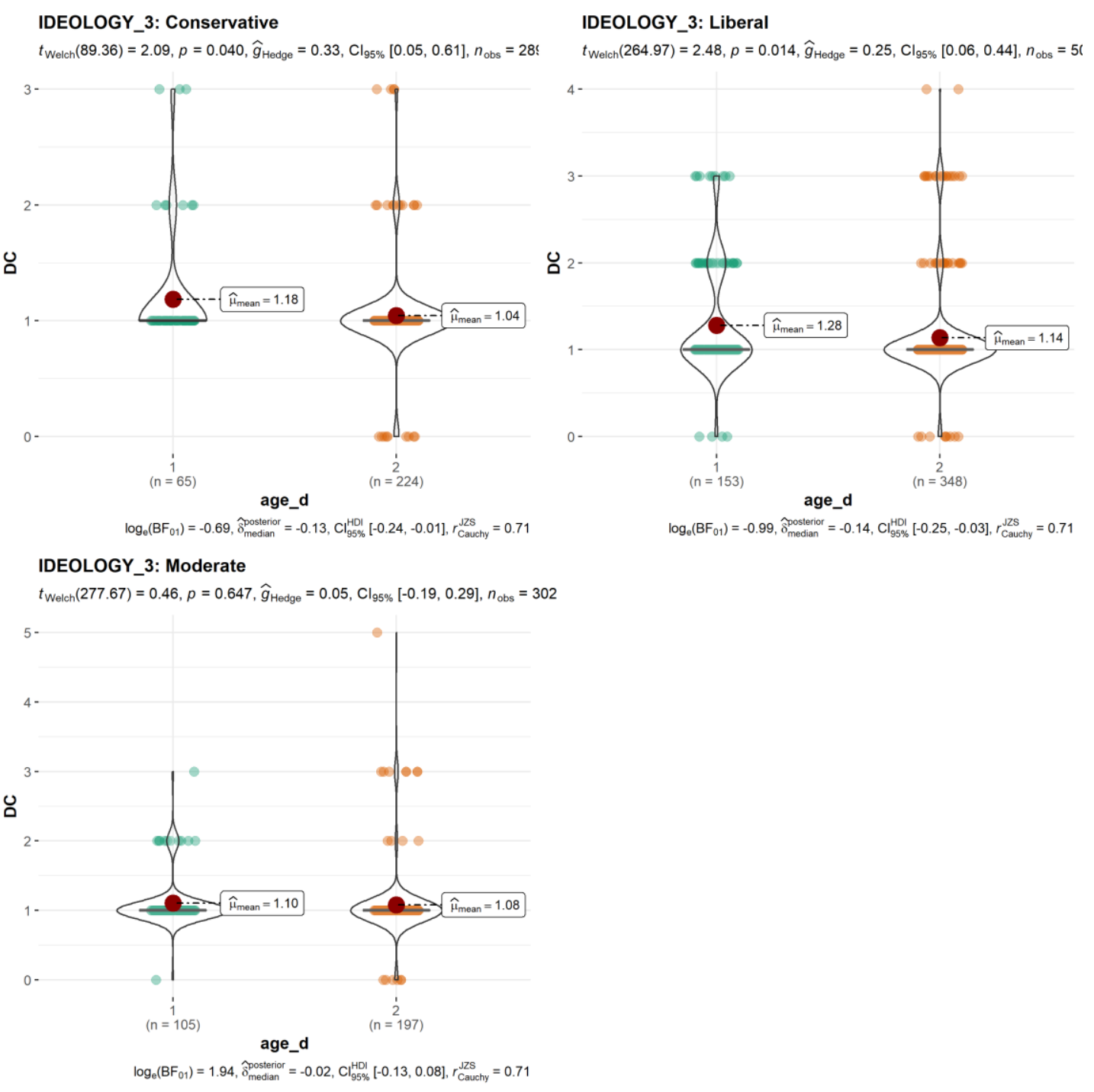

$\log _{e}\left(\mathrm{BF}_{01}\right)=-0.99, \widehat{\delta}_{\text {median }}^{\text {poster }}=-0.14, \mathrm{C}_{95 \%}^{\mathrm{HDl}}[-0.25,-0.03], r_{\text {Cauchy }}^{\mathrm{J} 2 \mathrm{~S}}=0.71$ 